\section{The arrow of time}

SIR - Huw Price's efforts to "demolish one of the main positive suggestions" in our book The Arrow of Time ${ }^{1}$ are flawed. In attempting to refute our arguments about the existence of entropy in chaotic systems, Price states that even if chaotic evolution destroys time-symmetric determinism, "what it leaves might well be time-symmetric indeterminism". But for highly unstable dynamical systems (including $\mathbf{K}$ flows and Bernoulli automorphisms, which are of considerable theoretical importance), the temporal symmetry is broken ${ }^{2,3}$.

It is precisely because of this time-asymmetric indeterminism that one can define an entropy-like quantity (or Liapounov variable) which has the property of monotonic increase with time. Moreover, the conditions under which such an entropy exists can be formulated rigorously in the language of ergodic theory in terms of intrinsic properties of a dynamical system ${ }^{2,3}$.

This approach avoids the problems associated with coarse-graining and initial condition arguments, which lead to 'entropies' that can decrease with time.

PETER COVENEY
Schlumberger Cambridge Rèsearch,
PO Box 153,
Cambridge CB3 OHG, USA

\section{The Daily Telegraph,} London E1, UK

Roger HighFIELD

\section{Humane killing} can only be because at some point it already treats the past and future orientations differently - otherwise the extra information would be redundant. Hence in this case any resulting asymmetry will effectively have been built into the theory from the beginning. So in neither case do we have 'sym- metry-breaking'; that is, a temporal asymmetry which arises where there was none before.

The argument is independent of the mathematical form of the theory concerned.

Traditional and Modern Philosophy, University of Sydney,

Australia 2006

SIR - In recent years, a better understanding of the animal, particularly in the physiological and ethological fields, has placed a greater emphasis on accountability and ethics with regard to the use of animals in experiments. The development of various methods of anaesthesia and humane killing which do not affect the data for an experimental study involving animals is therefore of the utmost importance. A number of effective methods exist ${ }^{1,2}$, but some of these affect the parameters of a study, are costly, not readily obtainable or simple distasteful.

I would like to draw attention to an alternative method of killing mice and rats that involves the intraperitoneal injection of 70 per cent ethanol ${ }^{3,4}$. The effects of 70 per cent ethanol on the central nervous system of mice and rats are similar to that of carbon dioxide. Upon injection, ethanol affects the acid-base balance by lowering blood $\mathrm{pH}$ and plasma bicarbonate concentration and increasing plasma lactate and ketone bodies. These changes result in respiratory and metabolic acidosis and cause depression of the central nervous system. This method is humane, inexpensive and very simple. In instances where barbiturate drugs would normally be used, such as vaccine candidate evaluation, 70 per cent ethanol may be of immense value as an alternative, particularly in developing countries where barbiturate drugs have limited availability. Physical methods such as dislocation of the neck might be used but requires expertise and is often distasteful to the researcher.

In the light of many recent articles published on animal experimentation ${ }^{5,6}$, a continuing concern for accountability with animal use will undoubtedly see the development of alternative and improve methods of anaesthesia and killing. Ethanol may be the first of many new techniques.

ROGER LORD

Malaria Vaccine Group,

The Queensland Institute of Medical

Research,

Bramston Terrace,

Herston, Queensland 4006 ,

\section{Australia}

\section{Gulf oil spill}

SIR - In his report on the Gulf oil spill caused by the Iraqi forces ${ }^{1}$, Peter Aldhous discusses the suitability of recent techniques of bioremediation for tackling this catastrophe. Bioremediation technology involves spraying beaches and floating oil with cocktails of oil-feeding bacteria and/or nutrients that stimulate indigenous oil-feeders. The Texas company Alpha Environmental and its UK sister Alpha Biological Treatment Services are said to be standing by to move tonnes of bacterial cocktail to the Gulf.

Our group has been involved in research on oil-degrading microorganisms in Kuwaiti soils and coastal waters. We have found that one bacterial genus, Rhodococcus ${ }^{2}$, predominates in the Kuwaiti (probably in the entire Gulf) environment, counting up to tens of millions of cells per gram of soil. Kuwaiti strains, which are adapted to the extreme environmental conditions of the region, proved much more active in oil degradation than strains isolated elsewhere. From the ecological point of view, the indigenous strains would severely compete with strains of the bacterial cocktail, and the oil-feeders could thus become antagonistic.

During oil degradation, bacteria frequently excrete specific detergents that may dramatically inhibit other oil-feeding strains $^{3}$. One may thus conclude that the most suitable approach would be the spraying of nutrients to stimulate indigenous oilfeeding strains. Enhanced oil degradation would probably then follow, but there is reason to believe that new environmental hazards would also arise. Rhodococcus, like many other oil-feeding actinomycetes, excretes large amounts of trehalose glycolipids as detergents. These compounds show a degree of toxicity ${ }^{4}$, and in addition, frequently contain mycolic acids, whose relation to pathogenesis is known ${ }^{5}$. In this context, it should be remembered that the Gulf is the main source of drinking water in this region.

With regard to the volume of oil released (about 1.5 million barrels), which turned out to be considerably less than at first assumed (about 10 million barrels), the concerned authorities might be better advised to tackle this catastrophe using the more tedious but safer physical means of oil removal from water.

\section{Department of Botany and}

SAMIR S. RADWAN*

Microbiology,

University of Kuwait,

PO Box 5969, Safat 13060, Kuwait

1. Aldhous, P. Nature 349, 447 (1991)

2. Sorkhoh, N., Ghannoum, M. A. Ibrahim, A. S., Stretton, R. J. \& Radwan, S. S. f. appl. Bact. 69, 856-863 (1990)

3. Fogth, I. M. Gutnick, D. L. \& Westlake, D. W. S. Appl environ. Microbiol. 55, 36-43 (1989).

Green, C. J. Animal Anaesthesia(Spottiswoode, Ballantyne,

2. Blackshaw J. K. \& Allan, D. J. Principles of Laboratory Anima Management, Australian Society for the Study of Anima Behaviour (University of Queensland, Australia, 1985).

Behaviour (University of Queensland,
3. Lord, R. Aust. Vet. J. 66, 268 (1989)

4. Lord. R., Jones G. L., Spencer, L. Res. Vet. Sci (in the press)

5. Good. R. A. Science 248, 538 (1990)

6. Hollands, C. Nature 339, 248 (1989).
4. Jardine I Scanlan G. Mc Neil, M. \& Brennan P. J anal. Chem. 61, 416-422 (1989).

5. Toubiana, R., Berlass, J. Sato, H. \& Strain, M. J. Bact. 139

* Present address: Von-Einem-Strasse 25, D-4400 Munster Germany.

NATURE · VOL $350 \cdot 11$ APRIL 1991 205-211 (1979). 